Jurnal Sulolipu : Media Komunikasi Sivitas Akademika dan Masyarakat

Vol. 19 No.2 2019

e-issn : 2622-6960, p-issn : 0854-624X

\title{
FAKTOR-FAKTOR YANG MEMPENGARUHI KEBIASAAN BUANG AIR BESAR SEMBARANGAN TEMPAT DI DESA BONTO JAI KECAMATAN BISSAPPU KABUPATEN BANTAENG
}

\author{
${ }^{1}$ Erlani, ${ }^{2}$ Ernawati \\ ${ }^{1,2}$ Jurusan Kesehatan Lingkungan Poltekkes Kemenkes Makassar \\ (erlanirappe66@gmail.com) \\ (erna.wati01976@gmail.com)
}

\begin{abstract}
Environmental health problems, especially in the disposal of feces, are one of the varieties of medical problems that need to get priority. The purpose of this research is to know the factors that affect the habit of bowel movements in the village Bonto Jai District Bantaeng. The research method is an observational method with a descriptive approach, using the Chi-Square test with a sample number of $113 \mathrm{KK}$. Based on the results of the study, the respondents were well-knowledgeable 64 KK (56,63\%) And the knowledgeable less 49 KK (43,37\%), respondents who are good 9 KK (7,97\%) And that is less $104 \mathrm{KK}(92,03 \%)$, respondents who have a good action $105 \mathrm{KK}(92,92 \%)$ And who have actions less $8 \mathrm{KK}(7.08 \%)$, respondents who have a high socio-economic 57 KK $(50,44 \%)$ While the respondents had a low socio-economic 56 KK $(49,56 \%)$, respondents who had the provision of clean water $111 K K(98.23 \%)$ While that does not have a clean water supply 2 KK (1.77\%). From the results of the study can be concluded that there is a relationship between knowledge, attitude, action and socio-economic to the habit of defecation in vain place and there is no connection between the provision of clean water with bowel habits The place. Advice is still needed to do environmental health counseling, especially about family latrines.

Keywords: the habit of bowel movements indiscriminately and feces
\end{abstract}

\section{ABSTRAK}

Masalah penyehatan lingkungan permukiman khususnya pada pembuangan tinja merupakan salah satu dari berbagai masalah kesehatan yang perlu mendapatkan prioritas.Tujuan dari penelitian ini adalah untuk mengetahui faktor-faktor yang berpengaruh terhadap kebiasaan Buang Air Besar Sembarangan Tempat di Desa Bonto Jai Kabupaten Bantaeng. Metode penelitian yaitu metode observasional dengan pendekatan deskriptif, menggunakan Uji Chi-Square dengan jumlah sampel yaitu sebanyak $113 \mathrm{KK}$. Berdasarkan hasil penelitian, responden yang berpengetahuan baik $64 \mathrm{KK}(56,63 \%)$ dan yang berpengetahuan kurang 49 $\mathrm{KK}(43,37 \%)$,responden yang bersikap baik $9 \mathrm{KK}(7,97 \%)$ dan yang bersikap kurang $104 \mathrm{KK}(92,03 \%)$, responden yang memiliki tindakan baik $105 \mathrm{KK}(92,92 \%)$ dan yang memiliki tindakan kurang $8 \mathrm{KK}(7,08 \%)$, responden yang memiliki sosial ekonomi tinggi 57 KK $(50,44 \%)$ sedangkan responden yang memiliki sosial ekonomi rendah 56 KK(49,56\%), responden yang memiliki Penyediaan Air Bersih 111KK (98,23\%) sedangkan yang tidak memiliki Penyediaan Air Bersih 2 KK (1,77\%). Dari hasil penelitian dapat disimpulkan bahwa ada hubungan antara pengetahuan, sikap, tindakan dan sosial ekonomi terhadap kebiasaan buang air besar sembarangan tempat dan tidak ada hubungan antara penyediaan air bersih dengan kebiasaan buang air besar sembarangan tempat. Saran yaitu masih perlu dilakukan penyuluhan kesehatan lingkungan khususnya tentang jamban keluarga.

Kunci : Kebiasaan Buang Air Besar Sembarangan dan Tinja

\section{PENDAHULUAN}

Derajat kesehatan masyarakat suatu Negara dipengaruhi oleh keberadaan sarana kesehatan. Undang-undang Nomor 36 tahun 2009 tentang kesehatan menyatakan bahwa fasilitas pelayanan kesehatan adalah suatu alat dan/atau tempat yang digunakan untuk menyelenggarakan upaya pelayanan kesehatan, baik preventif (pencegahan penyakit), promotif (peningkatan kesehatan), kuratif (penyembuhan penyakit), maupun rehabilitatif (pemulihan kesehatan) yang dilakukan oleh pemerintah, pemerintah daerah dan/atau masyarakat

Masalah penyehatan lingkungan pemukiman khususnya pada pembuangan tinja merupakan salah satu dari berbagai masalah kesehatan yang perlu mendapatkan prioritas. Penyediaan sarana pembuangan tinja masyarakat terutama dalam pelaksanaannya tidaklah mudah, karena menyangkut peran serta masyarakat yang biasanya sangat erat kaitannya dengan pengetahuan, sikap, tindakan, pendidikan, sosial ekonomi dan penyediaan air bersih

Terkait dengan BAB (Buang Air Besar) disungai,India berada di peringkat tertinggi di dunia, sedangkan Indonesia menduduki peringkat kedua atau tepatnya dibawah India. Fenomena masyarakat yang berada di daerah pedesaan, terutama yang dilalui sungai masih banyak yang berperilaku tidak sehat dengan buang air besar di sungai, pekarangan rumah, atau tempat-tempat yang tidak selayaknya (Notoatmodjo, 2007). Perubahan perilaku BAB (Buang Air Besar) ini tidak mudah. Sebagai contoh kalau sudah terbiasa $\mathrm{BAB}$ disungai yang kakinya terendam air, merasa dingin, melihat pemandangan dan terasa nyaman lalu harus berpindah BAB (Buang Air Besar) di WC dengan ruang yang sempit, kurangnya ventilasi dan gelap. Kebiasaan BAB di sungai sangatlah merugikan kesehatan masyarakat karena banyak warga yang melakukan aktivitas disungai seperti mandi dan mencuci baju 
Jurnal Sulolipu : Media Komunikasi Sivitas Akademika dan Masyarakat

Vol. 19 No.2 2019

e-issn : 2622-6960, p-issn : 0854-624X

Dampak penyakit yang ditimbulkan dari buang air besar disungai melalui feses yang terinfeksi mencemari air sungai dan terkontaminasi bibit penyakit yang berasal dari feses kemudian diminum manusia, bisa juga feses yang terinfeksi dihinggapi kecoa atau lalat kemudian hinggapi makanan maupun peralatan makan (piring, sendok, dan gelas) dan masih banyak orang yang mengambil air dikali untuk keperluan rumah tangga, padahal sejumlah penyakit menyebar melalui feses seperti diare, Typus abdominalis, kolera, disentri, hepatitis (Notoatmodjo, 2007).

\section{METODE \\ Desain, Tempat dan Waktu}

Variabel bebas adalah variabel yang dianggap berpengaruh terhadap variabel terikat dalam hal ini adalah pengetahuan, sikap, tindakan, sosial ekonomi, dan penyediaan air bersih, sedangkan Variabel terikat adalah variabel yang dipengaruhi oleh variabel bebas yaitu Kebiasaan Buang Air Besar Sembarangan tempat. Penelitian ini dilaksanakan di Desa Bonto Jai Kecamatan Bissappu Kabupaten Bantaeng. Di Desa Bonto Jai terdapat sebuah sungai dimana masyarakat sering melakukan aktifitas seperti mencuci, mandi dan membuang kotoran. Aktifitas tersebut sudah menjadi kebiasaan sebagian masyarakat yang ada di sana, dan kebiasaan itu sudah berlangsung sangat lama, oleh sebab itu peneliti ingin melakukan penelitian di Desa tersebut.

\section{Jumlah dan cara pengambilan subjek}

Yang menjadi populasi pada penelitian ini adalah seluruh kepala keluarga yang bertempat tinggal di Dusun Pati Desa Bonto Jai yaitu 158 KK. Jumlah sampel dalam penelitian ini sebanyak $113 \mathrm{KK}$. Pengambilan sampel dilakukan dengan cara simple random sampling dimana setiap orang mempunyai kesempatan untuk dijadikan sampel dalam penelitian ini .

\section{Jenis dan Cara Pengumpulan Data}

Jenis penelitian ini yaitu penelitian secara deskriptif yaitu data yang terkumpul dari hasil survey, observasi maupun jawaban dari kusioner yang dituangkan dalam bentuk tabel dan kemudian di analisa. Cara pengumpulan data yaitu Data primer diperoleh dengan cara observasi, kusioner dan wawancara langsung di lapangan kepada kepala keluarga yang bertempat tinggal di Desa Bonto Jai, data diperoleh dari daftar pertanyaan (kusioner). Sedanglan Data sekunder diperoleh dengan mengambil data dari kepustakaan, literatur-literatur, data dari puskesmas bissappu, dan data dari kantor Desa Bonto Jai, yang terkait dengan penelitian ini.

\section{Pengolahan dan Analisis data}

Pengolahan Data dalam penelitian ini ialah Data yang diperoleh dari daftar pertanyaan (kusioner) diolah dengan menggunakan SPSS.Penyajian Data yaitu di sajikan dalam bentuk tabel. Setelah data diolah kemudian di analisis dengan menggunakan uji statistik Chi-Square

\section{HASIL}

Bersadarkan hasil penelitian yang telah dilakukan di lokasi penelitian pada tanggal 7-11 April 2019 di Desa Bonto Jai Kecamatan Bissappu Kabupaten Bantaeng. Data primer diperoleh dari jawaban responden dari hasil pengamatan dan wawancara langsung kepada $113 \mathrm{KK}$ diperoleh hasil sebagai berikut :

Tabel 1

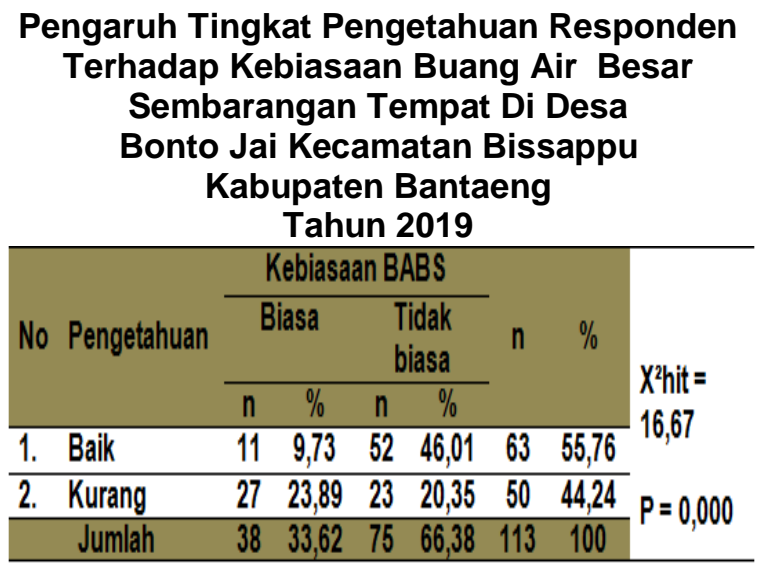

Tabel 2

Pengaruh Sikap Responden Terhadap Kebiasaan Buang Air Besar

Sembarangan Tempat Di Desa Bonto Jai Kecamatan Bissappu Kabupaten Bantaeng Tahun 2019

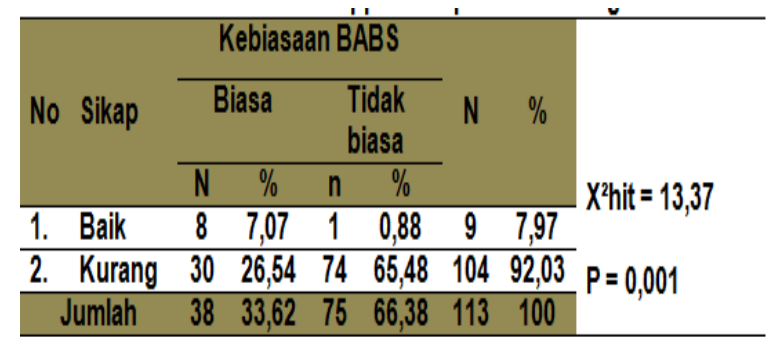


Jurnal Sulolipu : Media Komunikasi Sivitas Akademika dan Masyarakat

Vol. 19 No.2 2019

e-issn : 2622-6960, p-issn : 0854-624X

Tabel 3

Pengaruh Tindakan Responden Terhadap
Kebiasaan Buang Air Besar Sembarangan
Tempat Di Desa Bonto Jai Kecamatan
Bissappu Kabupaten Bantaeng Tahun 2019

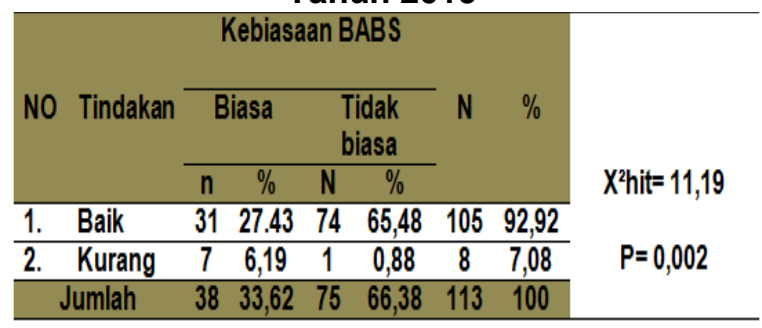

Tabel 4

Pengaruh Sosial Ekonomi Responden Terhadap Kebiasaan Buang Air Besar Sembarangan Tempat Di Desa Bonto Jai Kecamatan Bissappu Kabupaten Bantaeng Tahun 2019

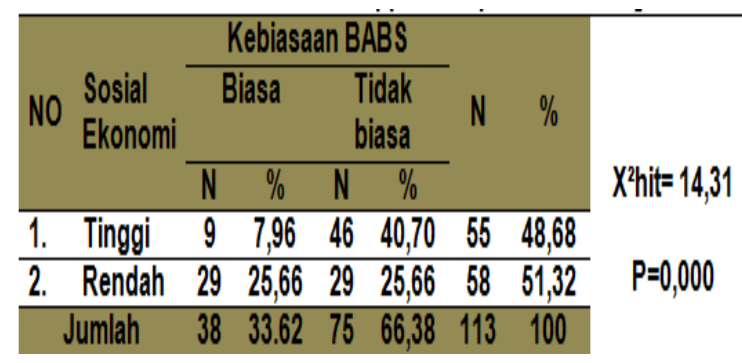

Tabel 5

Pengaruh Penyediaan Air Bersih Responden Terhadap Kebiasaan Buang Air Besar Sembarangan Tempat Di Desa Bonto Jai Kecamatan Bissappu Kabupaten Bantaeng Tahun 2019

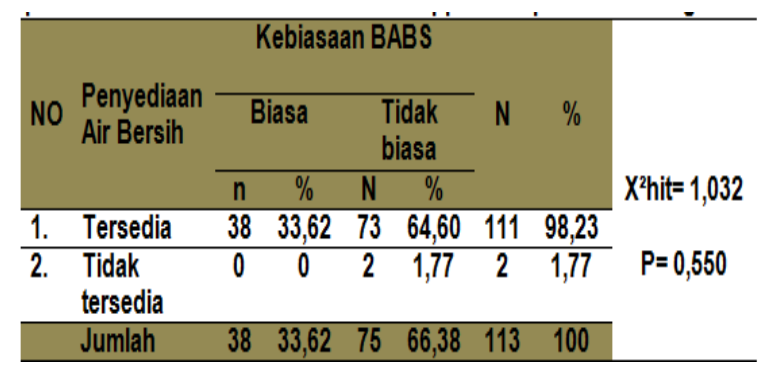

\section{PEMBAHASAN}

1. Pengetahuan Responden

Tingkat pengetahuan responden dan pengaruhnya terhadap kebiasaan Buang Air Besar sembarangan tempat. Responden yang berpengetahuan baik dapat memelihara jambannya dengan baik dibandingkan dengan responden yang berpengetahuan kurang baik hal ini menunjukkan bahwa pengetahuan merupakan faktor yang berpengaruh terhadap kebiasaan pembuangan tinja secara baik atau pun kurang baik.

Pengetahuan adalah hasil dari tahu,dan ini terjadi setelah orang melakukan penginderaan terhadap masalah suatu objek tertentu. Penginderaan terjadi melalui panca indera manusia, yakni penglihatan, pendegaran, penciuman, rasa dan peraba. Pengetahuan masyarakat dalam pembuangan tinja juga memerlukan suatu proses dalam melakukan perubahan. Perubahan ini dapat muncul disebabkan dengan kemajuan tehnologi. Notoadmodjo, 2007 )

Berdasarkan hasil uji statistik chi square untuk mengetahui bagaimana pengaruh tingkat pengetahuan dengan kebiasaan buang air besar sembarangan tempat di dapatkan hasil ada hubungan antara tingkat pengetahuan dengan kebiasaan buang air besar sembarangan tempat. Hal ini sesuai dengan penelitian Alhidayati (2016) dengan nilai $\mathrm{p}=0,000$ yang menyatakan bahwa ada hubungan antara pengetahuan dengan kebiasaan buang air besar sembarangan tempat, Ini disebabkan karena kurangnya pengetahuan masyarakat atau kurangnya informasi terkait dengan kesehatan lingkungan sehingga masyarakat tidak ada kesadaran dan kemauan untuk membuang tinja di jamban atau WC.

2. Sikap Responden

Sikap adalah respon tertutup seseorang terhadap stimulus atau objek tertentu, yang sudah melibatkan faktor pendapat dan emosi yang bersangkutan (senang-tidak senang, setuju-tidak setuju, baik-tidak baik, dan sebagainya).

Pada tabel diatas (2) sesuai dengan hasil penelitian yang dilakukan, dapat diketahui bagaimana pengaruh sikap terhadap kebiasaan buang air besar sembarangan tempat, dari $113 \mathrm{KK}$ terdapat $9 \mathrm{KK}(7,97 \%)$ dikategorikan bersikap baik dimana yang biasa buang air besar sembaragan tempat sebanyak $8(7,07 \%)$ dan yang tidak biasa buang air besar sembarangan tempat sebanyak $1 \mathrm{KK}(0,88 \%)$, sedangkan $104 \mathrm{KK}$ $(92,03 \%)$ dikategorikan bersikap kurang, dimana yang biasa buang air besar sebanyak $30 \mathrm{KK}(26,54 \%)$ dan yang tidak biasa buang air besar itu sebanyak $74 \mathrm{KK}(65,48 \%)$.

Berdasarkan hasil uji statstik Chi Square untuk mengetahui bagaimana pengaruh sikap dengan kebiasaan buang air besar 
Jurnal Sulolipu : Media Komunikasi Sivitas Akademika dan Masyarakat

Vol. 19 No.2 2019

e-issn : 2622-6960, p-issn : 0854-624X

sembarangan tempat di dapatkan ada hubungan antara sikap dengan kebiasaan buang air besar sembarangan tempat. Hal ini sesuai dengan penelitian Alhidayati (2016) dengan nilai $p=0,000$ yang menyatakan bahwa ada hubungan antara sikap dengan kebiasaan buang air besar sembarangan tempat. Hal ini disebabkan karena sikap responden yang suka membuang tinja sembarangan tanpa mereka mengetahui dampak atau bahaya yang bisa dtimbulkan ketika membuang air besar sembarangan tempat.

Berdasarkan hasil yang telah diperoleh, terlihat bahwa dari sekian responden yang menjawab tidak setuju atau bersikap kurang dan biasa buang air besar sembarangan tempat disebabkan karena kurangnya kesadaran dan kemauan yang dimiliki oleh masyarakat untuk hidup sehat. kebiasaan buang air besar ini sudah sejak dulu dilakukan, sebagian dari masyarakat memiliki jamb an tetapi masih melakukan kebiasaan buruk seperti $B A B$ di sungai, selokan, dan belakang rumah mereka lebih nyaman $B A B$ di tempat terbuka karena lebih mudah dan praktis daripada harus $B A B$ ditempat tertutup seperti di WC, dan sebagiannya lagi suka membuang tinja sembarangan tmpat karena memang mereka tidak memiliki jamban sehingga mereka memilih untuk membuang tinjanya sembarangan,hal ini disebabkan karena kurangnya kesadaran yang dimiliki masyarakat untuk membuat jamban keluarga, selain itu ekonomi yang rendah dan tidak tersedianya lahan untuk membuat jamban keluarga menjadi alasan masyarakat selalu buang air besar sembarangan tempat.

3. Tindakan Responden

Praktik adalah suatu sikap belum otomatis terwujud dalam suatu tindakan (Overt Behaviour). Untuk terwujudnya sikap menjadi suatu perbedaan nyata diperlukan faktor pendukung atau suatu kondisi yang memungkinkan, antara lain fasilitas. Di samping fasilitas diperlukan faktor dukungan (Support) dari pihak lain (Notoatmodjo, 2010).

Berdasarkan hasil penelitian yang dilakukan menunjukkan bahwa secara umum tindakan masyarakat dalam hal buang air besar sembarangan tempat sebanyak $38 \mathrm{KK}$ $(33,62 \%)$ dimana yang mempunyai tindakan baik dan masih melakukan buang air besar sembarangan tempat sebanyak $31 \mathrm{KK}$ $(27,43 \%)$ dan terdapat $7 \mathrm{KK}(6,19 \%)$ yang mempunyai tindakan buruk dan masih biasa membuang tinja sembarangan tempat, hal ini disebabkan karena masyarakat tidak memiliki jamban keluarga sehingga mereka lebih memilih membuang tinja sembarangan tempat seperti di sungai, kebun, belakang rumah maupun selokan dekat sawah, karena tersedianya lahan yang luas sehingga masyarakat lebih mudah dan praktis membuang tinjanya. Dan ada pula sebagian masyarakat yang sudah memiliki jamban namun masih melakukan buang air besar sembarangan tempat, hal ini disebabkan karena kebiasaan yang sulit diubah dan juga karena jarak sungai yang dekat sehingga mereka lebih memilih untuk BAB disungai karena lebih gampang dan praktis tanpa harus menggunakan air yang banyak.

4. Sosial Ekonomi Responden

Ekonomi adalah adanya ketidakseimbangan antara kebutuhan manusia yang tidak terbatas dengan alat pemuas kebutuhan yang jumlahnya terbatas.

Dari 113 responden yang diteliti beberapa responden yang sosial ekonominya tinggi masih memiliki jamban keluarga karena masih sanggup untuk membiayai pembuatan jamban/WC dengan rata-rata penghasilan diatas Rp 1.000 .000 perbulannya, sedangkan responden yang tidak memiliki jamban keluarga karena tidak mampu untuk membiayai pembuatan jamban/WC, dimana penghasilan yang diperoleh tiap bulannya kurang dari Rp 1.000.000, untuk memenuhi kebutuhan sehari-hari saja tidak cukup apalagi untuk membiayai pembuatan jamban/WC. Hal tersebut membuktikan bahwa responden yang berpendapatan tinggi lebih cenderung memiliki jamban keluarga sedangkan responden yang berpendapatan rendah lebih cenderung tidak memiliki jamban keluarga dikarenakan biaya yang kurang untuk pembuatan jamban keluarga.

Berdasarkan uji statistik dengan menggunakan chi square dengan nilai $p=$ 0,000 ini berarti bahwa ada hubungan sosial ekonomi dengan kebiasaan buang air besar sembarangan tempat. Hal ini Sesuai dengan penelitian Nyak Cut, 2013 dengan nilai $p=$ 0,00 yang menyatakan bahwa ada hubungan antara Ekonomi dengan kebiasaan pembuangan tinja masyarakat. Jadi sosial ekonomi merupakan salah satu faktor yang mempengaruhi kebiasaan buang air besar sembarangan tempat, karena semakin tinggi 
Jurnal Sulolipu : Media Komunikasi Sivitas Akademika dan Masyarakat

Vol. 19 No.2 2019

e-issn : 2622-6960, p-issn : 0854-624X

penghasilan responden maka semakin tinggi pula kemampuan responden untuk membuat jamban sehingga tidak lagi melakukan buang air besar sembarangan tempat jika sudah memiliki jamban. Selain itu hubungan sosial dengan masyarakatnya yang kurang bagus mereka tidak mempunyai inisiatif untuk saling berkerja sama dalam hal membangun jamban.

5. Penyediaan Air Bersih

Air bersih adalah air yang digunakan untuk keperluan sehari-hari yang kualitasnya memenuhi syarat kesehatan dan dapat diminum apabila telah dimasak.

Dari 113 responden yang diteliti hampir seluruh responden mempunyai penyediaan air bersih tetapi tidak memiliki jamban keluarga sehingga mereka masih membuang tinja sembarangan tempat hal ini disebabkan karena kebiasaan masyarakat yang selalu merasa lebih nyaman dan praktis membuang kotoran di sungai atau disembarangan tempat. Jadi dapat disimpulkan bahwa penyediaan air bersih tidak mempengaruhi kebiasaan buang air besar sembarangan tempat.

Penyediaan air bersih tidak memiliki pengaruh dengan kebiasaan buang air besar sembarangan tempat bagi masyarakat karena sumber air yang tersedia cukup untuk keperluan sehari-hari, namun masih ada masyarakat yang membuang tinja sembarangan tempat seperti di sungai, selokan dan bahkan ada yang membuang tinja dibelakang rumah, hal ini disebabkan karena masyarakat masih mempunyai kebiasaan buruk dan kurangnya pengetahuan tentang penyakit yang ditimbulkan jika selalu membuang tinja sembarangan.

\section{KESIMPULAN}

Berdasarkan hasil penelitian yang telah dilakukan tentang Faktor-Faktor Yang Mempengaruhi Kebiasaan Buang Air Besar Sembarangan Tempat Di Desa Bonto Jai Kecamatan Bissappu Kabupaten Bantaeng tahun 2019 dapat disimpulkan sebagai berikut :

1. Ada hubungan antara Pengetahuan, Sikap, Tindakan, Dan Sosial Ekonomi responden dengan Kebiasaan Buang Air Besar Sembarangan Tempat Di Desa Bonto $\mathrm{J}$ ai Kecamatan Bissappu Kabupaten Bantaeng.

2. Tidak ada hubungan antara penyediaan air bersih responden dengan Kebiasaan Buang Air Besar Sembarangan Tempat Di Desa Bonto Jai Kecamatan Bissappu Kabupaten Bantaeng.

\section{SARAN}

1. Masih perlu dilakukan penyuluhan kesehatan lingkungan khususnya tentang jamban keluarga agar masyarakat lebih mengerti dan mengetahui tentang pentingnya jamban keluarga serta dampak yang akan di timbulkan jika membuang tinja sembarangan tempat.

2. Diharapkan adanya pemantauan dan pendekatan secara khusus terhadap masyarakat yang tidak memiliki jamban jamban keluarga melalui pemberian motivasi dan dorongan agar masyarakat memiliki pemahaman, kesadaran dan kemauan untuk memiliki jamban keluarga

3. Sebaiknya petugas puskesmas lebih aktif lagi dalam hal pemantauan dan pemberian informasi seperti melakukan penyuluhan tentang kesehatan lingkungan khususnya pada masalah jamban keluarga

\section{DAFTAR PUSTAKA}

Alhidayati,dkk, 2016. Faktor-faktor yang berhubungan dengan kebiasaan Buang air besar sembarangan di wilayah kerja UPTD puskesmas Kampar kiri Hulu II Kabupaten Kampar tahun 2016. Lembaga penelitian dan pengabdian kepada masyarakat. Universitas Riau (Online) (https://repository.unri.ac.id) diakses tanggal 25 Mei 2019

Anna Dwiana dan Lucky Herawaty, 2017. Determinan Perilaku Buang Air Besar Pada Masyarakat Pesisir di Kabupaten Buton Selatan. BKM jurnal of community Medicine and public Health, Vol 33 No. $6 \mathrm{Hal}$ 273-276, (Online) (https://www.neliti.com) diakses tanggal 22 Desember 2018

Fitri Azis, 2006. Studi Tentang Perilaku Dengan Pola Hidup Bersih dan Sehat Masyarakat kelurahan Bontorannu Kecamatan Mariso Kota Makassar. Makassar : Program D-III Jurusan Kesehatan Lingkungan Politeknik Kesehatan Makassar. (KTI tidak diterbitkan) 
Jurnal Sulolipu : Media Komunikasi Sivitas Akademika dan Masyarakat

Vol. 19 No.2 2019

e-issn : 2622-6960, p-issn : 0854-624X

Muh Rijaluddin, 2013. Studi Pengetahuan, Sikap, Dan Pendidikan Masyarakat Terhadap Pemanfaatan Jamban Keluarga Di Desa Siawung Kecamatan Barru Kabupaten Barru tahun 2013. Makassar: Program D-III Jurusan Kesehatan Lingkungan Politeknik Kesehatan Makassar (KTI tidak diterbitkan).

Nurhalina sari, dkk. 2016. Faktor Yang Mempengaruhi Perubahan Perilaku Stop Buang Air Besar Sembarangan (BABS): Studi Pada Program STBM di Desa Sumbersari Metro Selatan 2016. Jurnal Dunia Kesmas, Vol 5 no. 3 hal $121-130$ (Online) (https://www.researchgate.net/publication/327930834) diakses tanggal 22 desember 2018

Nyak Cut, 2013. Faktor-Faktor Yang Mempengaruhi Kebiasaan Pembuangan Tinja Masyarakat Gampong Persiapan Rumoh Panyang Kecamatan Kuala Batee Kabupaten Aceh Barat Daya Tahun 2013. Fakultas Kesehatan Masyarakat. Universitas Teuku Umar Meulaboh.(Online).(http://repository.utu.ac.id/656/1/BAB\%20I_V.pdf) diakses tanggal 25 Mei 2019

Permenkes RI No. 32 Tahun 2017. Standar Baku Mutu Kesehatan Lingkungan Dan Persyaratan Kesehatan Air Untuk Keperluan Higiene Sanitasi, Kolam Renang, Solus Per Aqua, dan permandian

Umum.(Online).(http://hukor.kemkes.go.id/uploads/produk_hukum/PMK_No._32_ttg_Standar_Bak

u_Mutu_Kesehatan_Air_Keperluan_Sanitasi,_Kolam_Renang,_Solus_Per_Aqua_.pdf).diakses tanggal 22 desember 2018.

Sukarni Hardanensi, 2007. Hubungan Tingkat Pendidikan dan Pengetahuan Masyarakat Dengan Penggunaan Jamban Keluarga Attang Salo Kecamatan Ma'rang kabupaten Pangkep , Makassar: Program D-III Jurusan Kesehatan Lingkungan Politeknik Kesehatan Makassar (KTI tidak diterbitkan).

Wahyuni Sahani, dkk, 2018. Pedoman Karya Tulis Ilmiah Diploma III. Makassar : Kementerian Kesehatan Republik Indonesia Politeknik Kesehatan Makassar Jurusan Kesehatan Lingkungan

Windy Ardina, 2016. Persepsi Masyarakat Tentang Perilaku Buang Air Besar di Sungai di Desa Temon Kecamatan Ngrayun Kabupaten Ponegoro, Program Studi D-III Keperawatan Fakultas IImu Kesehatan Universitas Muhammadiyah Ponogoro. (Online) (http://eprints.umpo.ac.id/2272/) diakses tanggal 22 desember 2018. 